\title{
DA SÉRIE AO CIBER: O FOLHETIM TRANSMÍDIA DESAPALXONANTE, DE MARVIN CROSS
}

\author{
FROM SERIES TO CYBER: MARVIN CROSS'S DISASSEMBLE TRANSMEDIA LEAFLET
}

\author{
Ingrid Lara de Araújo Utzig ${ }^{1}$
}

RESUMO: $\mathrm{O}$ formato do folhetim originou o que hoje é conhecido como novelas e séries, por exemplo. Este artigo teve como objetivo analisar a obra Desapaixonante, de autoria de Marvin Cross, escritor maranhense radicado no Estado do Amapá. A narrativa se circunscreve dentro das características do folhetim e foi divulgada na internet, a priori, até ser publicada em livro físico pela editora Skull. Triangulando as teorias de Canclini (2016) sobre a estética da iminência e da perspectiva pós-autônoma da arte, em conjunto com a cultura da convergência defendida por Jenkins (2009) e a discussão a respeito da intermidialidade tratada por Clüver (2011), pretendeu-se compreender os percursos traçados por Marvin para a consolidação de um público leitor fiel de uma narrativa on-line fragmentada e as estratégias por ele usadas até a publicação impressa, a considerar que os efeitos econômicos e mercadológicos estão arraigados no ofício de escrever um produto cultural. Após a análise, foi possível perceber que o referido autor adotou a prática intermidial como base de sua própria estética da iminência, que consiste na transição entre plataformas, em movimentos de não permanência que são, na realidade, a multiplicação da presença em locais diferentes, o que acaba ampliando as possibilidades de acesso.

Palavras-chave: Desapaixonante; Estética da iminência; pós-autonomia; convergência; intermidialidade.

ABSTRACT: The French roman-feuilleton format originated what is known today by soap operas and series, for example. This article aimed to analyze the literary work Desapaixonante, authored by Marvin Cross, a Maranhão writer resident in the state of Amapá. The narrative is circumscribed within the characteristics of the French roman-feuilleton and it was publicized a priori on the internet, before being released in a physical book by Skull publishing company. Triangulating Canclini's (2016) theories on the aesthetics of imminence and the post-autonomous perspective of art, combining with the convergence culture proposed by Jenkins (2009) and the discussion of intermidiality presented by Clüver (2011), the research intended to understand Marvin's path towards consolidating a loyal readership of a fragmented online narrative and the strategies he used until the print, considering that the economic and marketing effects are rooted in the craft of writing a cultural product. After the analysis, it was possible to realize that the author adopted the intermidial practice as the basis of his own aesthetics of imminence, which consists on the transition between platforms, non-permanence movements that are, in fact, the multiplication of presence in different places, which ends up expanding the possibilities of access.

Keywords: Desapaixonante; Aesthetics of imminence; post-Autonomy; convergence; intermidiality.

\footnotetext{
1 Doutoranda do DINTER UNESP em convênio com as Universidades Federal e Estadual do AmapáUNIFAP/UEAP. Professora do Instituto Federal de Educação, Ciência e Tecnologia do Amapá-IFAP.
} 


\section{Introdução}

A ascensão do formato do folhetim traça um caminho estreitamente ligado a diversos marcos históricos, como o surgimento e a solidificação da classe burguesa e o fortalecimento da imprensa, advento tecnológico fruto de uma Revolução Industrial que, através das máquinas, consolidou os trabalhos jornalístico e literário.

Nesse mundo em (trans)formação, pautado em um modelo capitalista já bem estabelecido, é que o folhetim surge nas páginas de jornais franceses em meados do século XIX, mas ainda de maneira pouco definida, pois "os atributos que identificam o gênero folhetinesco não nascem prontos. São construídos dia a dia através das páginas dos jornais” (DINIZ, 2009, p. 78). Entretanto, já ia se desenhando essa característica principal que consiste na fragmentação episódica da narrativa, tática de venda que visava garantir a assiduidade de assinaturas. A partir daí, portanto, começa a tensão da relação literatura e mercado, uma vez que a história publicada também precisava seguir protocolos de leitura que deixassem a narrativa em uma sequência de capítulos, cuja periodicidade era rentável tanto ao suporte de divulgação quanto ao próprio escritor.

folhetim foi se tornando, assim, um produto direcionado ao consumo cultural popular, inserido cada vez mais em um contexto socioeconômico com a responsabilidade de gerar lucros. O grande desafio reside na ambiguidade de "encobrir e descobrir [...] sua duplicidade de objeto cultural e mercadoria” (CHALMERS, 1985, p. 139).

Bentes, Koch e Nogueira (2003) categorizam três principais movimentos de recepção, presentes na elaboração de folhetins: "o dispositivo da fragmentação da leitura, o da sedução e o da produção do reconhecimento" (p. 272), ou seja, há uma inserção e interação com o leitor, que se sente participante e envolvido por se enxergar na ficcionalização do cotidiano ali representado, uma vez que "queria algo ligado a seu cotidiano, desejava reconhecer a própria história romanceada, o que propiciou o desenvolvimento de uma literatura que viesse ao encontro do anseio de evasão desse público” (CAVALCANTE, 2005, p. 68).

Nessa perspectiva, "o folhetim adula o interesse do leitor, estabelecendo uma espécie de cumplicidade na satisfação dos desejos despertados pela narrativa” (CHALMERS, 1985, p. 136).

Tal contorno de reprodução foi alvo de críticas: debates sobre a qualidade do gênero e seu perfil de "literatura de massa" (CONVERSANI; BOTOSO, 2009, p. 176); nesse sentido, para muitos, o folhetim foi "acusado de ser um produto [...] comercial, sem muitas pretensões literárias, [...] subliteratura. Por adotar uma linguagem fácil, padronizada e com enredos repetidos, é menosprezado e carrega o estigma de apenas entreter, sem estimular o desenvolvimento intelectual do público” (DINIZ, 2009, p. 90). Vale lembrar que, no Brasil, escritores como Machado de Assis, José de Alencar e Nelson Rodrigues publicavam regularmente em jornais sob heterônimos.

Ao longo dos anos o folhetim vai se modificando de acordo com os veículos de comunicação; radionovela (folhetim sonoro), telenovela (folhetim audiovisual), webséries (folhetim digital), mantendo sua natureza e seu radical. Nessa interface, cabe pensar também a respeito de novas estratégias de veiculação, recepção e leitura de tal material. Aqui, pretende-se analisar tanto o aspecto formal dentro da constituição de caráter folhetinesco da obra 
Desapaixonante (doravante chamada apenas de DSPXNT, pois é como o autor e os leitores assim a nomearam), do escritor amapaense Marvin Cross, bem como os percursos de circulação desse mesmo compêndio em livro, perpassando os diferentes suportes eletrônicos (culminando no formato físico) utilizados pelo autor.

Para Gatto, o livro é uma instituição, pautada em relações hierárquicas, e o debate a respeito da literatura no ciberespaço deve circundar se há a "reconfiguração desta para que possa atender às necessidades emergenciais de uma cultura tecnológica, por meio da desterritorialização e nomadismo de formas das publicações impressas” (2006, p. 49). Nesse sentido, cabe perguntar qual o (não) lugar da literatura digital, cuja descentralização, ao mesmo tempo que permite a proliferação para todo o mundo, também pode perder-se ou ser esquecida em meio a outras infinitas informações em hipertextos. Não só isso: também cabe questionar o motivo pelo qual tantos escritores se encontram diante da opção da virtualidade, pois é inegável que a internet "estabeleceu novos e até então inesperados padrões para a comunicação de massa" (GOULART, 2014, p. 112).

Resta compreender as razões subjacentes a essas práticas recentes: se é pela comprovação do livro impresso enquanto instituição (utilizando a expressão alcunhada por Gatto) falida, ou pela dificuldade de acessar e publicar através dessa mesma instituição que possui, como previamente citado, relações hierárquicas e excludentes, em contraponto à internet, aparentemente mais democrática e online para vozes marginalizadas pelas grandes editoras. $\mathrm{Ou}$ ainda: se a internet serve, para esses autores, como uma efetiva rede de conexões para serem notados por essas mesmas editoras e convergirem seu trabalho para chegar ao livro impresso.

Canclini apresenta a existência de uma perspectiva pós-autônoma da arte, em que houve um movimento de deslocamento nas práticas artísticas, outrora limitadas a objetos e agora focadas em contextos para que, enfim, haja uma inserção das obras na mídia, nos espaços urbanos, no ciberespaço e na sociedade (2016, p. 24). Cada vez mais o artista (aqui interessa, em especial, o escritor) passa a sair da noção fechada de campo de atuação para então expandi-lo em um exercício interdisciplinar: o escritor de hoje se expulsa da zona solitária e independente do momento da criação e interage com o leitor/consumidor através de diferentes estratégias, a fim de explorar o marketing cultural, não ignorando "o processo de produção-circulação-consumo". (2016, p. 49)

De que maneira Marvin Cross manipula sua série, dentro do que Canclini compreende como estética da iminência? Que trajetos, fluxos, modelos de acesso e suportes tecnológicos são experimentados pelo autor? Primeiro, apresentaremos o objeto deste estudo e, após isso, trataremos de termos textuais e contextuais da obra.

\section{2 "Cross" the lines: sobre o autor e a obra}

Marvin Cross é o nome usado por Marcos Vinícius Borges para assinar seus trabalhos. Natural do Maranhão, reside em Macapá (AP) desde criança. Além de escritor, é professor de Inglês na rede pública e em escolas de idiomas. A estreia de DSPXNT em livro físico ocorre em 2018, mas está em desenvolvimento desde 2015 e é sua segunda publicação, precedida pelo livro Missão Poesia (2013). Além disso, Marvin também já organizou dois e-books, coletâneas com 
jovens autores amapaenses. São eles: Se7e Estações Poéticas (2012) e Mosaico dos Raros (2014).

DSPXNT é uma narrativa de caráter folhetinesco que já foi concluída em quatro temporadas. A primeira, segunda e terceira temporadas possuem onze episódios cada, e a última, mais longa, foi fechada com dezoito. A história traz um slogan: "eles são tipo o cupido. Só que ao contrário". Primordialmente caracterizada como uma comédia (herdada da coloquialidade instaurada pela origem do folhetim em si), os narradores são os personagens Sávio e Milena, microempresários e sócios da ANNA (Agência do Negócio Nada Apaixonante), em homenagem à primeira mulher pela qual Sávio se apaixonou. Cada capítulo é um caso e trata de diferentes clientes que chegam à agência, necessitando de serviços que visam o desencantamento e o desinteresse forçado.

\section{Descaminhos desapaixonantes: percursos da série}

Tendo como base os estudos genettianos, compreende-se que a voz narrativa foi fragmentada como artifício para dialogar com o formato de séries televisivas, conforme será abordado com mais profundidade em seguida. Tratam-se, na realidade, de vozes, pois variam entre autodiegética (os episódios são, na maioria dos casos, intercalados entre as falas oriundas ou de Sávio ou de Milena), e homodiegética, como descrito no episódio 01x11 (denominado "Fabi), no qual há a narração feita por Sávio, Milena, mas também por Enzo, namorado de Milena. Percebem-se momentos de focalização externa, porém a ocorrência mais forte é de focalização interna variável, como se fossem cortes de câmera em que há diferentes zooms alternando o destaque na perspectiva das personagens, assemelhando-se à técnica de $\mathrm{POV}^{2}$ em clips privados, bastante utilizada em fanfictions.

\section{EPISÓDIO 11 - FABI}

(Do diário de Milena Kerber, 28 de junho de 2015, às 14:52)

[...] Hoje Enzo e eu vamos sair pra jantar. Vai ser um saco, como sempre. Tenho certeza que ele deve me levar ao restaurante de comida italiana que abriu perto da casa dele. Já ensaiei dezoito vezes na frente do espelho o sorriso que vou fazer para a selfie que ele vai querer tirar pra postar nas redes sociais. Enzo previsivel [...].

(Narrado por Enzo)

É hoje. Hoje é o dia. Hoje. [...] Pensei muito nisso, e hoje finalmente tomarei uma atitude. O que será que ela vai achar? Será que estou sendo muito precipitado? [...] Será que ela vai gostar do presente? [...] Será muito cedo [...]?

(Narrado por Sávio)

Plena segunda-feira e nada da Milena aparecer. Estou rodando na cadeira giratória em minha sala, lendo uma $\mathrm{HQ}$ antiga do Batman, enquanto

\footnotetext{
${ }^{2}$ Point Of View (ponto de vista).
} 
aparentemente o dia está calmo. [...] Mas o tempo passa, eu leio umas dez páginas dos quadrinhos [...] e o silêncio está reinando absoluto no escritório da ANNA. Cadê a Milena? (CROSS, 2018, p. 95-97)

Entretanto, o alvo principal de análise quanto à estrutura do texto são as categorias da ordem e do tempo (frequência e duração), uma vez que compõe a estratégia formal de envolvimento do leitor dentro do discurso folhetinesco, em que a sequência de eventos é recortada a partir da serialização. Considerando que o fatiamento da narrativa recompensa a fidelidade do espectador, é preciso acompanhar cada capítulo para os desdobramentos a longo prazo (JENKINS, 2009, p. 118).

Em DSPXNT, certos ganchos vão garantindo que o leitor sempre consiga se situar. Na abertura da série, ao final já se explicita o uso de uma prolepse, quando Sávio conclui o primeiro caso e pensa: "mal posso esperar o próximo caso" (CROSS, 2018, p. 10). Essa aplicação de flashforward é uma técnica que reaparecerá no episódio 01x03, em que Sávio mais uma vez soluciona um caso e se empolga: "E esse meu emprego? Bem, cada caso é adrenalina pura. E a excitação pelas próximas 'aventuras' só cresce” (CROSS, 2018, p. 27).

Além disso, o episódio 01x05, intitulado A Coisa tá Ruiva, já antecipa que será dividido em parte I e II. Ainda pautando a interpretação na teoria genettiana, notam-se vários protocolos de leitura espalhados por toda a história, manifestando uma preocupação para que o leitor consiga se localizar. O discurso repetitivo se dá porque:

o leitor precisa internalizar um grande número de informações [...], pois quando o próximo capítulo for publicado, ele já não terá acesso ao anterior. Por isso, os autores de folhetim se utilizam do recurso da [...] redundância [...] para reativar memórias, esclarecer certas situações ao leitor e permitir que ele identifique [...] momentos anteriores da trama para que reconheça uma situação posterior. (HEINZ, 2014, p. 37)

Na parte II, após todos os eventos narrados na parte I, Sávio retoma o que ocorreu anteriormente, através de analepse (flashback), realizando um sumário para estabelecer um vínculo mais próximo com o passado.

\section{EPISÓDIO 06 - A COISA TÁ RUIVA (parte 2)}

(Narrado por Sávio)

[...] Finalmente abro os olhos, não tenho ideia de onde estou. Tudo que me lembro é de ter saído do meu carro para ajudar um cara enquanto vigiava o namorado da Maitê, a ruiva [...]. Foi quando apareceram outros caras pra supostamente ajudar e, do nada, alguém veio por trás e cobriu minha cabeça com algum tipo de saco. No entanto, depois rolou um apagão, o que indica que provavelmente me deram uma porrada na cabeça [...]. Que horas são? Onde estou? Hoje ainda é hoje? Vão mesmo fazer outro filme dos Transformers ou só tive um pesadelo? (CROSS, 2018, p. 47)

Os mecanismos mencionados, como retomadas, resumos, antecipações para deixar em tensão o suspense para a continuação, estão limitados à esfera do texto, mas já estabelecem um 
elo para a manutenção cativa de audiência. Todavia, existem várias outras fórmulas para suprir a interatividade e a participação do leitor, bem como consolidar a narrativa através de divulgação massiva. Marvin perscruta o ciberespaço à procura de uma oportunidade de tornar DSPXNT acessível a todos. A primeira temporada foi inicialmente postada na íntegra no blog de Marvin, em seguida no aplicativo Wattpad ${ }^{3}$, para depois se transformar em e-book ${ }^{4}$ (vendido no site da Amazon, onde já se encontram disponíveis todas as quatro temporadas completas) e por fim em livro físico, com o selo da Editora Skull. Os exemplares da tiragem de estreia já foram esgotados ${ }^{5}$, o contrato para lançamento da segunda temporada impressa foi assinado, e a Skull dará continuidade à publicação da websérie-folhetim.

FIGURA I - Episódio piloto de DSPXNT

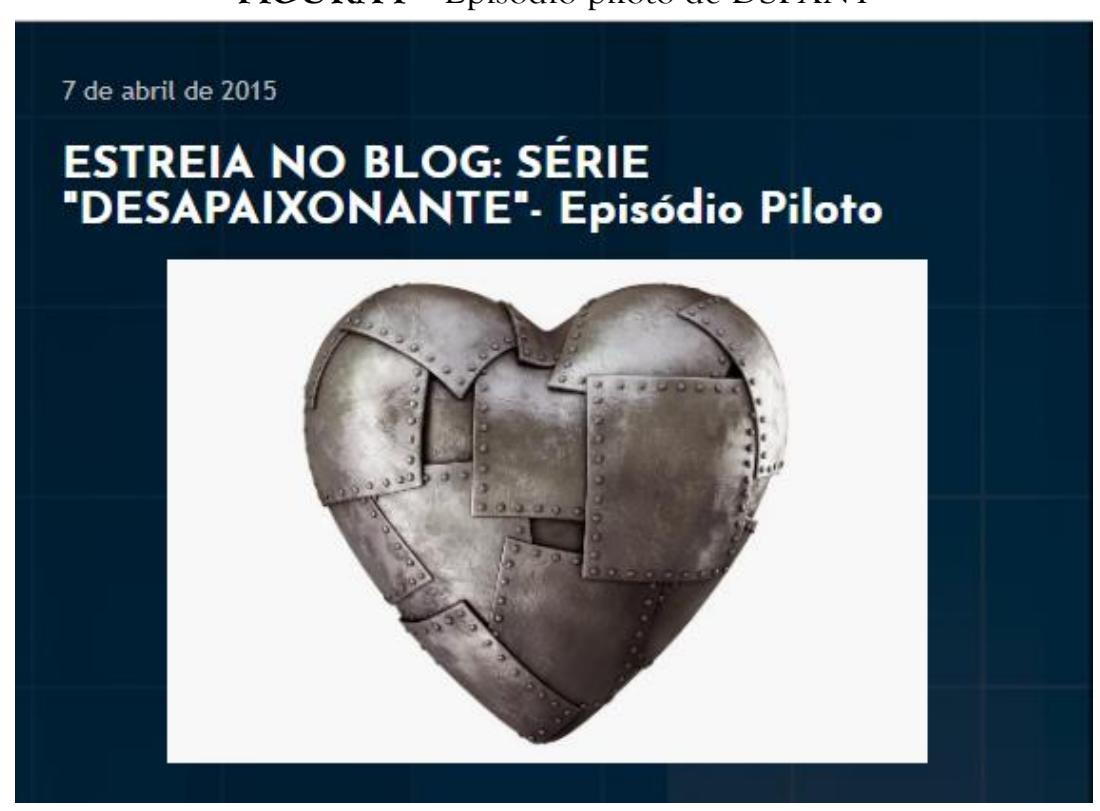

Fonte: Blog de Marvin Cross ${ }^{6}$.

A escolha de linguagem aplicada por Marvin (chamar episódios em vez de capítulos, por exemplo) é explicada por ele em uma entrevista ao blog Vai Lendo:

[...] achei inovador brincar com essa união entre literatura e algo fora dos formatos literários. O que eu faço é imaginar as cenas como se elas fossem ser reproduzidas em vídeo, mas moldadas de forma literária, já que este é o veículo pelo qual a história chega ao público. Geralmente, eu projeto/planejo episódio por episódio, com tópicos sobre o que será tratado em cada um,

\footnotetext{
${ }^{3}$ Com o slogan "onde as histórias criam vida", o app permite o uso em computadores ou dispositivos móveis, como celulares e tablets. Os usuários podem comentar, postar suas próprias histórias, votar e participar de grupos. As histórias mais acessadas aparecem diariamente em destaque na homepage. Anualmente, a plataforma promove o concurso literário "Prêmios Wattys".

${ }^{4}$ Além da Amazon, outros sites como Submarino, Estante Virtual, Americanas, Shoptime e Mercado Livre também comercializam DSPXNT.

${ }^{5}$ Disponível em: <http://www.lojaeditoraskull.com.br/romance/Desapaixonante-Primeira-Temporada>. Acesso em 29 abr. 2019.

${ }^{6}$ Disponível em: <http://marvincross.blogspot.com/2015/04/estreia-no-blog-serie-desapaixonante.html>. Acesso em 28 abr. 2019.
} 
criando um elo entre eles, mas mantendo a ideia de uma série procedural, ao mesmo tempo em que estou contando uma só história. Os episódios são escritos separadamente porque, quando a história surgiu, a ideia foi postar um episódio por semana (outra influência das séries de TV) e, ao final de cada temporada, eu junto os arquivos num só, como se compusessem um único livro. Cada temporada seria um livro. Os desafios de se escrever nesse formato são a estranheza com que algumas pessoas recebem a história, mas elas se acostumam logo. Eu diria que outro desafio é o mesmo enfrentado por milhões de outros escritores, que é a fragmentação da série em vários volumes, o que dificulta o acesso às editoras, por exemplo. E, no meu caso, prefiro manter a história dividida em volumes mesmo. A leitura, no entanto, flui semelhantemente a qualquer outra. Desapaixonante poderia ser encarado como diversas trilogias, quadrilogias e séries por aí, no sentido de cada livro deixar pontas soltas para os próximos. (2017)

O episódio número um, batizado de piloto, já mostra a inspiração televisiva, demonstrando a prática intermidial na construção da história. Clüver (2011) elucida esse conceito: “intermidialidade' implica todos os tipos de interrelação e interação entre mídias; uma metáfora frequentemente aplicada a esses processos fala de 'cruzar as fronteiras' que separam as mídias" (p. 2).

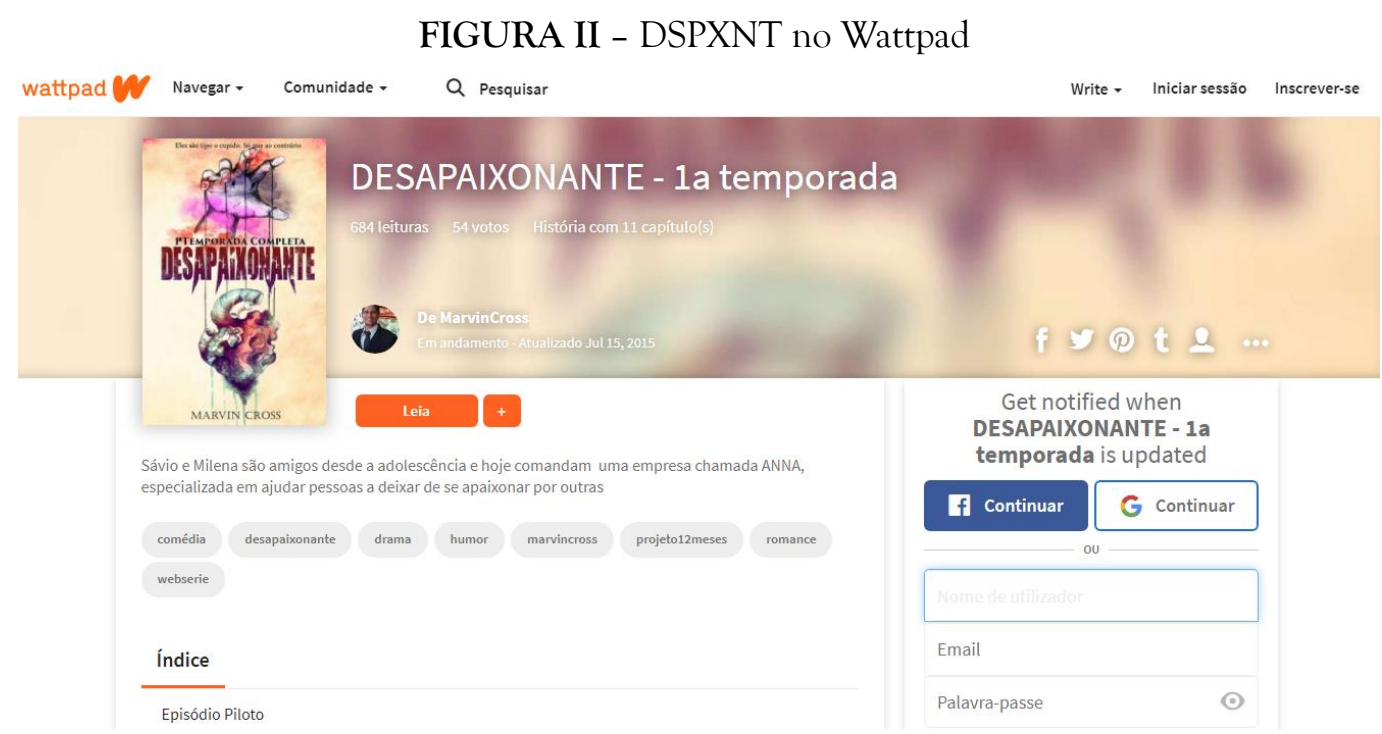

Fonte: Perfil de Marvin Cross.

No final do livro impresso, nas últimas páginas, existem os Extras: making of, onde o escritor comenta a "roteirização" de cada uma das histórias que compõem o volume I, e entrevistas com os protagonistas Milena e Sávio, reforçando a presença de gêneros híbridos na narrativa. O autor até elabora alguns "especiais" ao final de cada season, como o episódio comemorativo de um ano de DSPXNT, em que uma das personagens, Rita, realiza entrevista com o próprio Marvin. Nessa mesma lógica, lançou-se também o conto (como se fosse um spinoff $f^{7}$ ) ANNA para o Kindle, tratando do início da agência, uma vez que a narrativa original, em

\footnotetext{
7 Termo usado para tratar de histórias paralelas e derivadas do enredo principal, geralmente concentradas em aspectos que não são detalhados na narrativa macro. No caso do conto ANNA, trata-se de uma pré-sequência,
} 
si, foca nos casos dos clientes, em uma empresa já solidificada.

Marvin, ao evocar qualidades de outras mídias para o texto literário, aplica referências intermidiáticas, conforme a teoria de Rajewsky (2012). Ela demonstra que, atualmente, muitos romances e quadrinhos adotam técnicas e métodos que são característicos do cinema, por exemplo; no ambiente digital, esses processos de remediação migram de maneira ainda mais dinâmica.

Não bastando a hibridização da websérie enquanto folhetim digital baseado na linguagem televisiva, a narrativa também está cheia de citações com bordões oriundos da cultura pop e de músicas, que foram compiladas pelo autor de DSPXNT em uma playlist homônima, no Spotify ${ }^{8}$; fica a critério do leitor investigar e conhecer todas essas alusões textuais para além do que está escrito.



Fonte: Conta de Marvin Cross no Spotify ${ }^{9}$.

No prefácio do livro, Marvin apresenta seu projeto, reforçando aquilo que entende como a importância e a originalidade de DSPXNT:

Antes de ser enviada para avaliações de editoras, Desapaixonante - $1^{a}$ temporada completa foi postada em um blog que eu possuo e na plataforma Wattpad, para ser testada entre diversos tipos de leitores. A quantidade de reações positivas [...] me compeliu a ir em busca e uma publicação impressa, por acreditar no potencial da narrativa. (2018, p. 6)

Após receber retorno, através de comentários em um estudo experimental nos mencionados suportes eletrônicos, ocorreu o lançamento dos e-books pela Amazon e a procura por resenhistas especializados para divulgação mais eficaz da obra, seja através de blogs ou vlogs.

dedicada a explicar o passado que culminou no presente dos eventos narrados em DSPXNT.

${ }^{8}$ Serviço de streaming de músicas, podcasts e vídeos mais utilizado no mundo; acessível para computadores e dispositivos móveis em quaisquer sistemas operacionais.

${ }^{9}$ Disponível em: <open.spotify.com/playlist/4u43Xi7UQyiuqadLlzWk6m>. Acesso em 29 abr. 2019. 
Entre as resenhas postadas, destacam-se as das blogueiras Nanda de Marins, Flávia Bergamin (do Você é Tão Livro), e dos canais Pronome Interrogativo (de Thaís Cavalcante), Literarte (de Yasmim Braga), Um Livro Após o Outro (de Isabella Kurokawa Sanches) e Livraneios (de Nanna). No site do Skoob ${ }^{10}$, DSPXNT coleciona 14 resenhas.



Fonte: Perfil de Pronome Interrogativo no Youtube.

Em um post antigo de seu blog pessoal, intitulado "Por que Desapaixonante ainda não virou livro físico?", Marvin explica, entre outros assuntos, a relevância de contatar profissionais para comentarem sua história:

[...] existem muitos produtores de conteúdo literário que ajudam e muito no sucesso de um livro. Blogs, Perfis no Instagram e canais no Youtube são os principais deles, e suas resenhas e opiniões contribuem significativamente para que mais pessoas cheguem até o seu material. São pessoas apaixonadas por leitura, carismáticas, articuladas e que agregam outras pessoas que levam em consideração seus elogios ou críticas a todo tipo de obra literária. E o que isso tem a ver comigo? Encontrei muitos dispostos a me ajudar, o que acabou realmente acontecendo e trazendo mais visibilidade ao meu livro. [...] Porém, chegar até essas pessoas não é fácil. A princípio, algumas das que eu conheci possuem Mídia Kit, [...] pacote de serviços onde, mediante pagamento de determinados valores, você descola a chance para que o seu livro ocupe um espaço em suas redes sociais, seja para uma divulgação breve, uma menção

\footnotetext{
${ }^{10}$ Rede social colaborativa nacional, na qual os leitores listam livros já concluídos, em andamento ou os que estão em sua "lista de desejos". Nesse site também é possível avaliar as obras (de uma a cinco estrelas), bem como publicar resenhas com a opinião sobre os livros da base de dados.
} 
num vídeo ou uma resenha exclusiva. Não reprovo, pois essas pessoas têm competência para isso e estão corretas em valorizar seu trabalho, mas em geral não tive como arcar com vários dos valores que me foram propostos. Felizmente, entre serviços pagos e não pagos, a imensa maioria colaborou comigo por puro amor e admiração. (CROSS, 2017, s. p.)

Para otimizar os resultados e interagir melhor com o público, o autor criou contas em redes sociais, como Instagram (@desapaixonante_oficial) e uma fanpage no Facebook, em que o autor elabora memes e conteúdos humorísticos e criativos para engajamento dos seguidores.

FIGURA V - Memes de DSPXNT

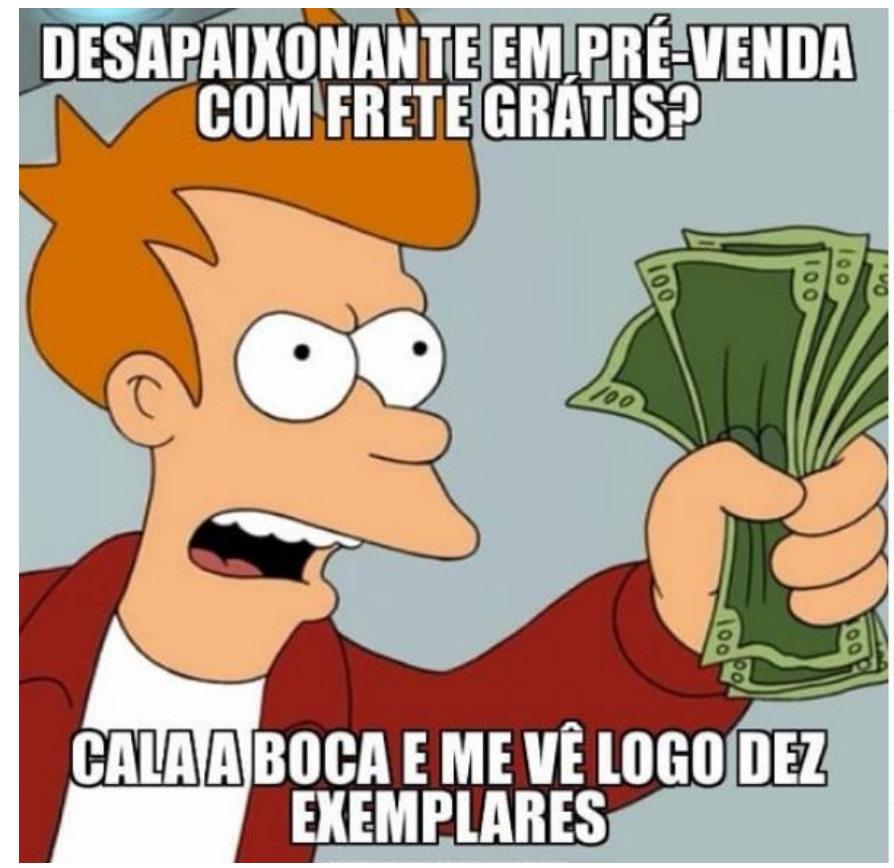

4 desapaixonante_oficial • Seguindo ...

desapaixonante_oficial De uma coisa eu sei: os memes não podem parar. kkkk. Já comprou seu exemplar de Desapaixonante hoje? Além de estar com um preço muito legal no site da (iskulleditor as colo legal no site da @ĩu Brasil. Aproveite a chance!! Link na bio.

29 sem

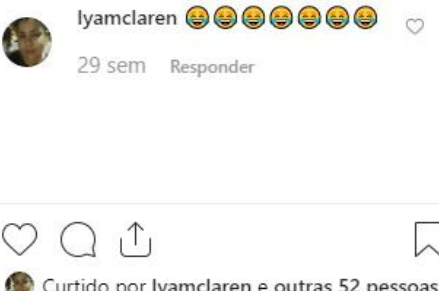

(8) Curtido por lyamclaren e outras 52 pessoas 5 DE OUTuBro DE 2018

Fonte: Perfil oficial no Instagram ${ }^{11}$.

Jenkins, em Cultura da Convergência, discute a narrativa transmídia como um novo jeito de contar histórias, por meio do "cruzamento criativo" entre os meios de comunicação através de um circuito de entretenimento multiplataforma ${ }^{12}$. Nesse percurso, Jenkins expõe que as narrativas estão em um nível de crescimento que não se esgota plenamente em um único volume, ou em uma só mídia (2009, p. 161). Investe-se, cada vez mais, não simplesmente em personagens que sustentam várias histórias, como também na elaboração de universos ficcionais. Assim, outras estruturas narrativas se formam e se expandem de modos complexos que não se fecham no clássico ciclo início-meio-fim, requerendo uma segmentação do conteúdo, no intuito de "testar que combinação melhor se adequa a seu público" (AZEVEDO; ROCHA, 2018, p. 111). Ratificando essa necessidade, Zanetti (2013) percebe que:

No âmbito da produção e circulação, se, por outro lado, as séries de TV possuem divulgação garantida [...], as webséries, por sua vez, dependem do

\footnotetext{
${ }^{11}$ Disponivel em: 〈https://www.instagram.com/p/BokiLcxh1Sk/>. Acesso em 29 abr. 2019.

${ }^{12}$ Expressão cunhada por Danny Bilson, vice-presidente de desenvolvimento de propriedade intelectual da Electronics Arts.
} 
próprio público para se espalharem pela rede. Além disso, devem estar vinculadas a outros sítios, como blogs e páginas em redes sociais, como forma de garantir maior visibilidade e poder de viralização [...], integrar as mídias e manter a fidelidade do público por meio da criação de narrativas transmidiáticas. (p. 85)

Continuando nessa hospedagem múltipla de DSPXNT em meio à rede, Marvin pôs à venda um e-book com a edição única de todas as quatro temporadas. A ideia, segundo ele, é de se aproximar do conceito de box de séries, mantendo a proposta original, de assemelhar a narrativa literária à linguagem televisiva.

FIGURA VI - E-book volume único de DSPXNT

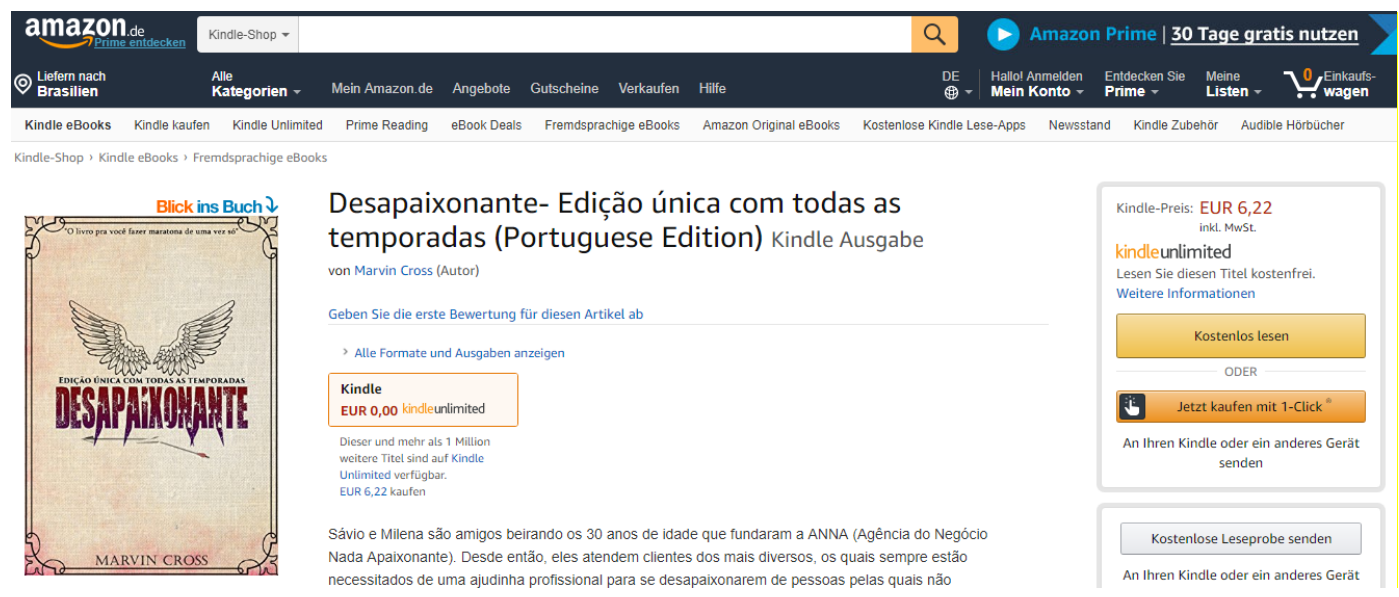

Fonte: Site oficial da Amazon ${ }^{13}$.

A ideia de compêndio de volumes distintos em um só livro é mais frequente em obras físicas do que em e-books. Como exemplo cita-se a pentalogia Inferno Provisório, do mineiro Luiz Ruffato, que após lançar todos os cinco livros, recebeu uma edição econômica pela Companhia das Letras, em 2016. A fragmentação da narrativa possui prós e contras, e um dos riscos é o de se perder audiência caso se estenda por muito tempo, então a condensação da história pode ser um fator que amenize o conflito na relação com o leitor impaciente. Foi pensando em tal perfil que Marvin optou por oferecer mais essa escolha ao leitor/consumidor/internauta. Foi uma decisão do autor, mas muitas vezes se torna uma imposição das editoras, que veem uma oportunidade de não perder compradores, pois nem sempre é certo que quem adquire o primeiro tomo dará continuidade e obterá todos.

\section{Considerações iminentes}

Pesquisas sobre a temática aqui tratada também interessam aos estudos literários, a partir da aceitação de que "a noção de autor fica subsumida na publicidade, na mídia" (CANCLINI, 2016, p. 24). A arte em geral, e a literatura, já não habitam pairando na superioridade do espírito do poeta inspirado, mas encontram-se inseridas em um modelo

\footnotetext{
${ }_{13}$ Disponível em: <https://www.amazon.de/Desapaixonante-Edi\%C3\%A7\%C3\%A3o-\%C3\%BAnica-temporadasPortuguese-ebook/dp/B07BBFZ3QJ>. Acesso em 07 mai. 2019.
} 
socioeconômico irreversivelmente integrado à cultura. Cabe, portanto, pensar no escritor como empreendedor, e o ciberespaço compõe esse experimentalismo artístico que permite "desfrutar os novos modos de acesso" (CANCLINI, 2016, p. 246).

Marvin, na mesma postagem supracitada ("Por que Desapaixonante ainda não virou livro físico?"), aborda não somente a questão das resenhas virtuais, como explica alguns dos percalços, dificuldades e desafios de lançar a obra através de alguma editora. Na época, ele ainda não havia conseguido fechar o contrato com a Skull e explicava aos leitores o motivo da demora, justificando que o autor precisa chamar a atenção da editora, que isso requer criatividade e esforço, e conclui, dizendo que não queria pintá-las como vilãs, pois são, antes de tudo, empresas, e que não se cogita investir em algo sem garantia de lucro e retorno. Por fim, Marvin fecha o texto afirmando que continuaria tentando publicar a série até quando se esgotassem todas as suas chances (CROSS, 2017).

No projeto de "esgotar todas as chances", explicitado pelo escritor, entende-se que Marvin, como um produtor de conteúdo situado na conjuntura de uma arte pós-autônoma, aceitou o "processo tecnológico de convergência digital e da formação de hábitos culturais diferentes em leitores que, por sua vez, são espectadores e internautas” (CANCLINI, 2008, p. 21). Nesse panorama, adotou a prática intermidial como base de sua própria estética da iminência, que consiste na transição entre plataformas, em movimentos de não permanência que são, na realidade, a multiplicação da presença em locais diferentes, o que acaba ampliando as possibilidades de acesso e desfrute à obra. Capaz de seduzir a atenção mercadológica e convergir o digital com o analógico, a interatividade da narrativa se manifesta desde texto de caráter folhetinesco, que já envolve e conta com a participação do leitor em uma continuidade dialógica, e se mantém no contexto de circulação e apropriação desse objeto literário, que já tendo sido publicado por uma editora, ainda não se esgotou ou se encerrou em si mesmo enquanto produto cultural aberto a táticas de distribuição e manipulação ainda não cogitadas.

\section{Referências}

AZEVEDO, P. A. R. O.; ROCHA, L. L. F. Do broadcast ao streaming: mudanças (não tão grandes) nas narrativas ficcionais seriadas. Revista Cambiassu, São Luís/MA, v. 13, n. 21, pp. 100 112 - Jan/Jun. 2018.2 Disponível em: <www.periodicoseletronicos.ufma.br/index.php/cambiassu/article/view/10429/6029>. Acesso em 01 mai. 2019.

BENTES; A. C.; KOCH, I. G. V.; NOGUEIRA, C. M. A. Gênero, mídia e recepção: sobre as narrativas televisivas e seus espectadores. Cad. Est. Ling., Campinas, v. 44, pp. 265-282, Jan./Jun. 2003. Disponível em: <http://repositorio.unicamp.br/bitstream/REPOSIP/118768/1/ppec_8637081-6822-1PB.pdf>. Acesso em 19 abr. 2019.

BERGAMIN, F. Resenha: Desapaixonante, de Marvin Cross. 2018. Disponível em: <http://voceetaolivro.com.br/2018/01/resenha-desapaixonante-de-marvin-cross/>. Acesso em 29 abr. 2019. 
BRAGA, Y. Original e Divertido: Desapaixonante, Marvin Cross. Literarte, 2018. 3:56 min. Disponível em: 〈https://www.youtube.com/watch?v=62oozeB7jTY>. Acesso em 30 abr. 2019.

CANCLINI, N. G. A Sociedade sem Relato: antropologia e estética da iminência. Tradução de Maria Paula Gurgel Ribeiro. 1. ed. São Paulo: Editora da Universidade de São Paulo (EDUSP), 2016.

CANCLINI, N. G. Leitores, espectadores e internautas. Tradução: Ana Goldberger. - São Paulo: Iluminuras, 2008. Disponível em: <https://d3nv1jy4u7zmsc.cloudfront.net/wpcontent/uploads/itau_pdf/000726.pdf $>$. Acesso em 08 mai. 2019.

CAVALCANTE, M. I. Do romance folhetinesco às telenovelas. OPSIS - Revista do NIESC, v. 5, pp. 63-74, 2005. Disponível em: 〈https://www.revistas.ufg.br/Opsis/article/view/9407/6483>. Acesso em 01 mai. 2019.

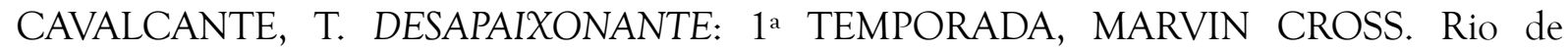
Janeiro: Pronome Relativo, 2017. 7:48 min. Disponível em: <https://www.youtube.com/watch?v=Ug2i8CGvkts>. Acesso em 29 abr. 2019.

CHALMERS, V. M. A Literatura fora da lei: um estudo do folhetim. Coleção Remate de Males, Campinas, v. 05, pp. 135-144. 1985. Disponível em: <https://periodicos.sbu.unicamp.br/ojs/index.php/remate/article/view/8636363/4072>.

Acesso em 22 abr. 2019.

CLÜVER, C. Intermidialidade. Pós: Belo Horizonte, v. 1, n. 2, pp. 8 - 23, nov. 2011. Disponível em:<https://www.eba.ufmg.br/revistapos/index.php/pos/article/view/16/16>.

Acesso em 29 abr. 2019.

CONVERSANI, Â. A. B.; BOTOSO, A. Do romance-folhetim às minisséries e telenovelas. Iluminart: Sertãozinho, v. 1, n. 3, pp. 175-185, dez. 2009. Disponível em: <http://revistailuminart.ti.srt.ifsp.edu.br/revistailuminart/index.php/iluminart/article/view/5 3/55>. Acesso em 01 mai. 2019.

CROSS, M. Desapaixonante: $1^{a}$ temporada. 1. ed. São Paulo: Editora Skull, 2018.

CROSS, M. Blog de Marvin Cross. Disponível em: <http://marvincross.blogspot.com/>. Acesso em 28 abr. 2019.


<https://www.wattpad.com/story/44815962-desapaixonante-1a-temporada>. Acesso em 28 abr. 2019.

CROSS, M. Fanpage Desapaixonante - Marvin Cross. Disponível em: <https://www.facebook.com/Desapaixonante-Marvin-Cross-1915656022043114>. Acesso em 29 abr.

CROSS, M. Playlist: Desapaixonante. 2019. 180 min. Disponível em: <https://open.spotify.com/user/12186746105/playlist/4u43Xi7UQyiuqadLlzWk6m?>. Acesso em 29 abr. 2019.

CROSS, M. Perfil @desapaixonante_oficial. Disponível em: <https://www.instagram.com/desapaixonante_oficial/?hl=pt-br>. Acesso em 30 abr. 2019. 
D'ARÊDE, J. Marvin Cross mostra como se 'desapaixonar' em narrativa em formato de série. 2017. Disponível em: <https://www.vailendo.com.br/2017/02/10/marvin-cross-mostra-como-sedesapaixonar-em-narrativa-em-formato-de-serie/>. Acesso em 27 abr. 2019.

DINIZ, J. A. A recriação dos gêneros eletrônicos analógico-digitais: radionovela, telenovela e webnovela. Tese (Doutorado em Comunicação Social) - Pontifícia Universidade Católica do Rio Grande do Sul (PUCRS), Porto Alegre, 2009. Disponível em: <https://docs.google.com/viewerng/viewer?url=http://tede2.pucrs.br:80/tede2/bitstream/tede /4386/1/418506.pdf>. Acesso em 19 abr. 2019.

GATTO, S. M. G. Literatura Brasileira e as Novas Tecnologias: Leitura e Produção. Revista de Estudos da Modernidade e da Contemporaneidade, São Bernardo do Campo - SP, v. 01, pp. 47-67, Jan./Jun. 2006.2 Disponível em: <http://www.orfeuspam.com.br/Periodicos_JL/Revista_Dialogos.pdf\#page=47>. Acesso em 22 abr. 2019.

GENETTE, G. Discurso da Narrativa. Tradução: Fernando Cabral Martins. 3. ed. Lisboa: Vega, 1995.

GOULART, F. O ontem e o hoje da indústria cultural: Do folhetim aos vlogs e redes sociais. Intuitio, Porto Alegre, v. 7, n. 2, pp. 104-121, nov. 2014. Disponível em: <http://revistaseletronicas.pucrs.br/ojs/index.php/intuitio/article/view/17409/12369>.

Acesso em 22 abr. 2019.

HEINZ, N. W. Fanfictions e folhetins: a comunicação através das narrativas serializadas. TCC (Bacharelado em Comunicação Social) - Universidade Federal do Rio Grande do Sul (UFRGS), Porto Alegre, 2014. Disponível em: <https://www.lume.ufrgs.br/bitstream/handle/10183/102357/000932435.pdf?sequence=1\& is Allowed=y $>$. Acesso em 01 mai. 2019.

JENKINS, H. Cultura da Convergência. Tradução: Susana L. de Alexandria. 2. ed. São Paulo: Aleph, 2009.

MARINS, N. de. Resenha: Desapaixonante - Marvin Cross. 2017. Disponível em: <http://www.nandademarins.com/2017/10/resenha-desapaixonante-marvin-cross.html>.

Acesso em 29 abr. 2019.

RAJEWSKY, I. O. Intermidialidade, intertextualidade e "remediação": uma perspectiva literária sobre a intermidialidade. In: DINIZ, T. F. N. (org.). Intermidialidade e estudos interartes: desafios da arte contemporânea. Belo Horizonte: Editora UFMG, 2012.

SANCHES, I. K. Resenha "DESAPAIXONANTE", MARVIN CROSS. São Paulo: Um Livro Após o Outro, 2017. 7:17 min. Disponível em: <https://www.youtube.com/watch?v=sZ1MHkhJ2QQ>. Acesso em 30 abr. 2019.

SKOOB. Resenhas - Desapaixonante, $1^{\text {a }}$ temporada completa. Disponível em: <https://www.skoob.com.br/livro/resenhas/633032/mais-gostaram>. Acesso em 29 abr. 2019. 
SILVA, G. S. DESAPAIXONANTE (MARVIN CROSS). São Paulo: Livraneios, 2017. 3:41 min. Disponível em: <https://www.youtube.com/watch?v=mGfoHzTP_dY>. Acesso em $30 \mathrm{abr}$. 2019.

ZANETTI, D. Webséries: narrativas seriadas em ambientes virtuais. Revista GEMInIS, São Carlos (SP), ano IV, v. 1, pp. 69-88, 2013. Disponível em: <http://www.revistageminis.ufscar.br/index.php/geminis/article/view/128/100>. Acesso em 01 mai. 2019.

Recebido em: 25/07/2019

Aceito em: 16/09/2019 